University of Nebraska - Lincoln

DigitalCommons@University of Nebraska - Lincoln

Faculty Publications from the Department of Electrical \& Computer Engineering, Department Electrical and Computer Engineering

$11-1-2004$

\title{
Parametric investigation of laser nanoimprinting of hemispherical cavity arrays
}

L. P. Li

University of Nebraska-Lincoln

Yongfeng Lu

University of Nebraska-Lincoln, ylu2@unl.edu

D. W. Doerr

University of Nebraska-Lincoln

Dennis R. Alexander

University of Nebraska-Lincoln, dalexander1@unl.edu

X. Y. Chen

National University of Singapore

Follow this and additional works at: https://digitalcommons.unl.edu/electricalengineeringfacpub

Part of the Electrical and Computer Engineering Commons

Li, L. P.; Lu, Yongfeng; Doerr, D. W.; Alexander, Dennis R.; and Chen, X. Y., "Parametric investigation of laser nanoimprinting of hemispherical cavity arrays" (2004). Faculty Publications from the Department of Electrical and Computer Engineering. 93.

https://digitalcommons.unl.edu/electricalengineeringfacpub/93

This Article is brought to you for free and open access by the Electrical \& Computer Engineering, Department of at DigitalCommons@University of Nebraska - Lincoln. It has been accepted for inclusion in Faculty Publications from the Department of Electrical and Computer Engineering by an authorized administrator of DigitalCommons@University of Nebraska - Lincoln. 


\title{
Parametric investigation of laser nanoimprinting of hemispherical cavity arrays
}

\author{
L. P. Li, Y. F. Lu, ${ }^{\text {a) }}$ D. W. Doerr, and D. R. Alexander \\ Department of Electrical Engineering, University of Nebraska, Lincoln, Nebraska 68588-0511 \\ X. Y. Chen \\ Department of Electrical and Computer Engineering, National University of Singapore, 4 Engineering \\ Drive 3, Singapore 117576, Singapore
}

(Received 29 January 2004; accepted 31 July 2004)

\begin{abstract}
A monolayer of self-assembled silica particles can be imprinted into a silicon substrate by laser irradiation $(\mathrm{KrF}$ excimer laser, $\lambda=248 \mathrm{~nm})$. Periodical hemispherical cavities can be therefore created on the substrate surface. The influences of various particle sizes and laser fluence were investigated. In addition, preheating of the substrate significantly improves the performance. One-dimensional thermal calculation was employed to understand the thermal effect in this process. Three-dimensional optical simulation provided an accurate insight into the light intensity enhancement. Raman spectroscopy was used to examine the stress induced by the laser imprinting process resided in the cavity structures. (C) 2004 American Institute of Physics.
\end{abstract}

[DOI: $10.1063 / 1.1796515]$

\section{INTRODUCTION}

Photons interact with materials with a periodic variation in the refractive index in a similar way to electrons with crystalline solids. ${ }^{1}$ Since the concept of the photonic band gap (PBG) was introduced, the dream to integrate a large amount of photonic crystals on one chip with reduced size for an all-optical circuit, combining high integration and high speed processing, ${ }^{2}$ has drawn a lot of interest and research in recent years. Various scientific and engineering applications, such as zero-threshold lasers, control of spontaneous emission, and sharp-bend light waveguides, ${ }^{3}$ are expected by using the PBG crystals. Although three-dimensional (3D) crystals are ideal to manipulate the propagation of light, fabrication of $2 \mathrm{D}$ PBG crystals is the first step toward this aim.

Various nanolithography techniques have been developed to produce 2D periodic structures on solid surfaces. Electron beam lithography is able to form high resolution of submicron features. ${ }^{4-6}$ However, serial processing limits the throughput and the cost is high. X-ray lithography has high throughput $^{7,8}$ but it requires a high capital cost. UV photolithography ${ }^{9,10}$ is a widely used method; however, its feature sizes are limited by its diffraction limit of $\lambda / 2$ (Ref. 11). For the laser-assisted nanopatterning with scanning tunneling microscope ${ }^{12}$ or atomic force microscope, ${ }^{13}$ good feature size control can be obtained but the sample throughput is low. A number of new approaches for nanofabrication have been developed. Among them, nanoimprinting lithography has demonstrated to pattern sub-10 $\mathrm{nm}$ features over a large area in a few minutes. ${ }^{6,14}$ This technique utilizes a reusable stamp to pattern resist, followed by directional dry etching. ${ }^{15}$ Nevertheless, since electron beam lithography is needed to make the stamp, the process cost is high.

\footnotetext{
${ }^{a)}$ Author to whom correspondence should be addressed; FAX: (402) 4724732; electronic mail: ylu2@unl.edu
}

Therefore, developing PBG crystal technology is still a challenge since inexpensive, inherently parallel, and highthroughput techniques are yet to be established. In this work, an approach to fabricate well-ordered, nanoscale 2D periodic arrays using laser nanoimprinting of self-assembled nanoparticles on solid surfaces was developed. Since this technique is a parallel process using self-assembly technique, stamps are not required and therefore cost is significantly reduced. At the same time, large scale photonic structures can be simultaneously formed in a few seconds by the laser nanoimprinting. In this study, the dependence of fabricated structures on particle size, laser fluence, and substrate temperature has been investigated. The cavity structures were characterized by scanning electron microscopy (SEM). Onedimensional thermal calculation revealed that the cavity array is formed due to the particles imprinted into the substrate while the substrate is being melted by laser irradiation. Three-dimensional optical simulation was employed to predict the optical field distribution. The light intensity enhance-

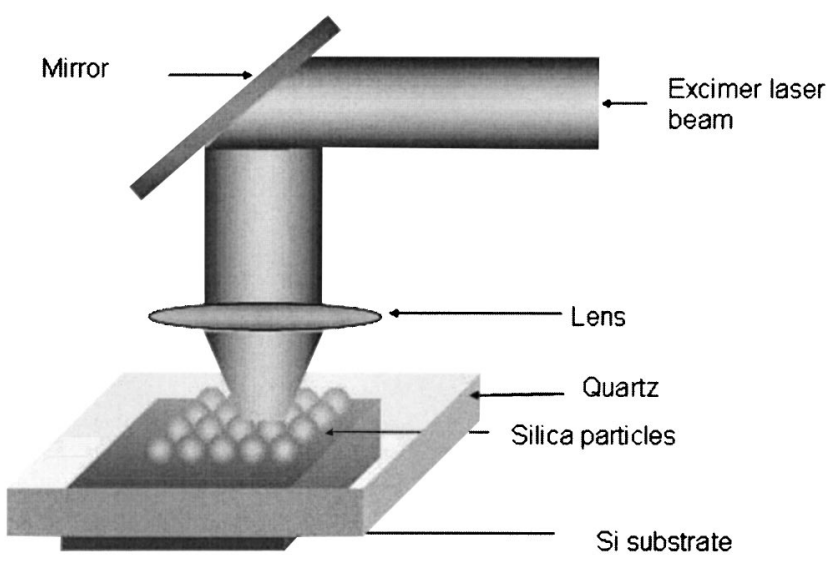

FIG. 1. Schematic diagram of nanoparticle monolayer nanoimprinting setup. 

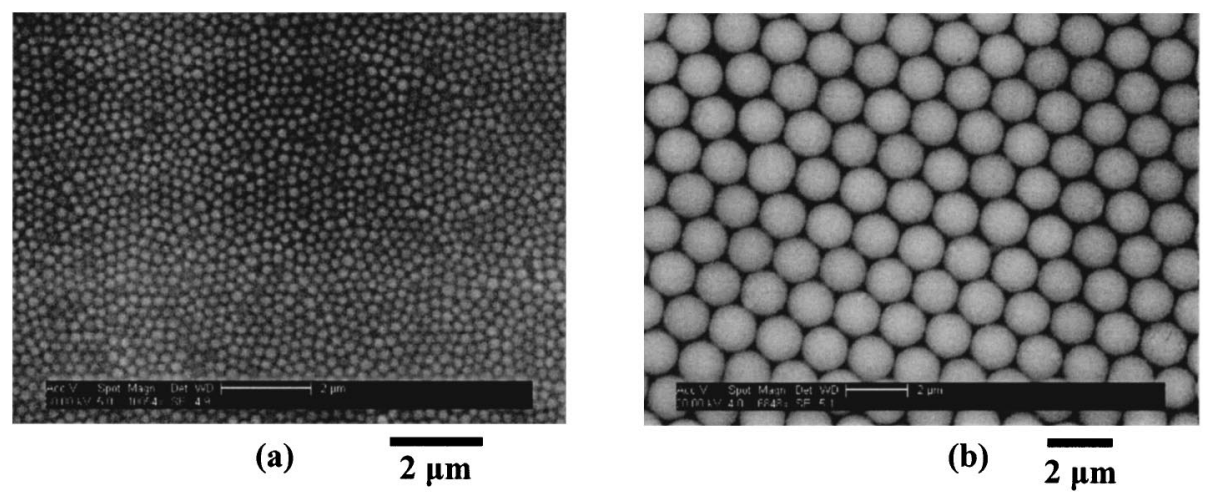

FIG. 2. SEM images of silica particle monolayers: (a) $0.3 \mu \mathrm{m}$ particles and (b) $1.54 \mu \mathrm{m}$ particles.

ment exists between the particle and the substrate. An extremely high temperature is therefore produced on the particle-substrate contacting point. ${ }^{16}$ Raman spectroscopy was further carried out to characterize the stress in the cavity structures.

\section{EXPERIMENTAL DETAILS}

The (100) silicon wafers were cleaned by a standard process. To eliminate the influence of the oxidation on the substrate surface, the substrates were cleaned by hydrofluoric (HF) acid to remove the oxide layer before the experiment and then rinsed by deionized water. Many techniques for the self-assembly of nanoparticles, such as spin-coating and tilting method, have been investigated. ${ }^{17-19}$ In this work, tilting method was used. Surfactant (triton-X: methanol=1:400) was dropped onto the tilted substrate surface and the substrate was left to dry at room temperature. The purpose of using surfactant was to help wet the substrate. ${ }^{20}$ Monodisperse sphere suspensions (Bangs Laboratories, Inc.) were subsequently dispensed onto the substrate. The sphere suspensions have silica $\left(\mathrm{SiO}_{2}\right)$ particles with a solid percentage of $10 \%$ suspended in water. For systematic investigation of the laser nanoimprinting process, particles with various diameters ranging from 0.16 to $5 \mu \mathrm{m}$ were used in the experiment. Hexagonally close-packed monolayers of particles were formed on the Si surface by this tilting method. A quartz plate was firmly placed on the sample surface to tightly press the self-assembled nanoparticle monolayer. The

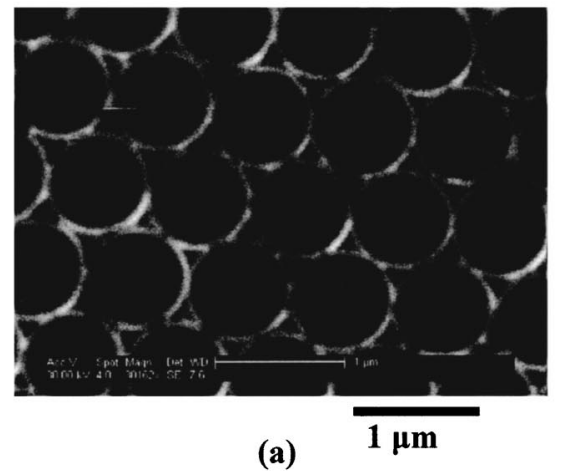

light source was a $\mathrm{KrF}$ excimer laser with a wavelength of $248 \mathrm{~nm}$ and a pulse duration of $17 \mathrm{~ns}$. The quartz plate is transparent to the laser wavelength of $248 \mathrm{~nm}$. The excimer laser beam was focused into a smaller area by a convex lens and normally irradiated the quartz/nanoparticle/substrate structure (Fig. 1). The laser fluence ranged from 0.35 to $1.7 \mathrm{~J} / \mathrm{cm}^{2}$. Each sample was irradiated with a single pulse. The silica particles were imprinted into $\mathrm{Si}$ substrates during the laser irradiation. After laser irradiation, the silica particles which were remained on the sample surface were removed by ultrasonic cleaning and HF solution. Hemispherical cavities were produced on the Si substrate surface. The sample surface before and after the laser irradiation was characterized by SEM. The effect of preheating substrate was also investigated. The samples were preheated to various temperatures.

\section{RESULTS AND DISCUSSION}

\section{A. Self-assembly of silica particles on Si substrates}

Hexagonally arranged, close-packed arrays of silica particles were self-assembled on a $\mathrm{Si}$ substrate. Figure 2(a) shows a typical SEM micrograph of the monolayer for silica particles of $0.3 \mu \mathrm{m}$. The particle diameter has a deviation up to a range of $\pm 10 \%$. This pattern is not uniform because of the wide size distribution of the $0.3 \mu \mathrm{m}$ silica particles. Figure 2(b) shows the morphology of self-assembled silica particles with diameter of $1.54 \mu \mathrm{m}$.

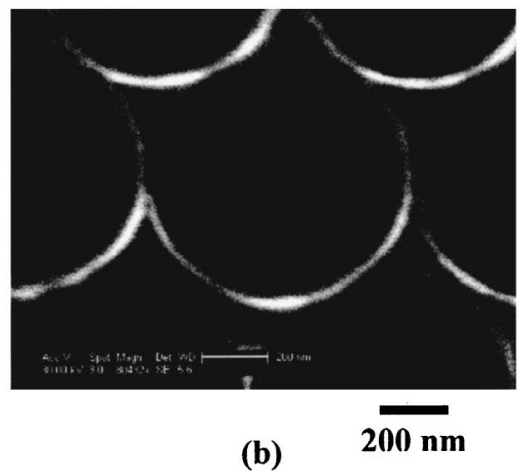

FIG. 3. SEM images of periodic cavity arrays formed after laser irradiation of $0.97 \mu \mathrm{m}$ silica particles on a Si substrate by a single laser pulse with a fluence of $0.85 \mathrm{~J} / \mathrm{cm}^{2}$. 


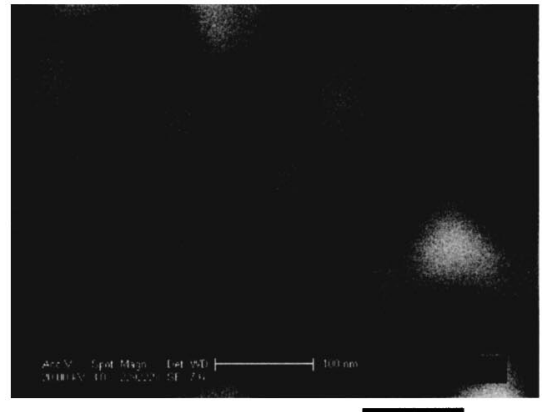

(a)

$100 \mathrm{~nm}$

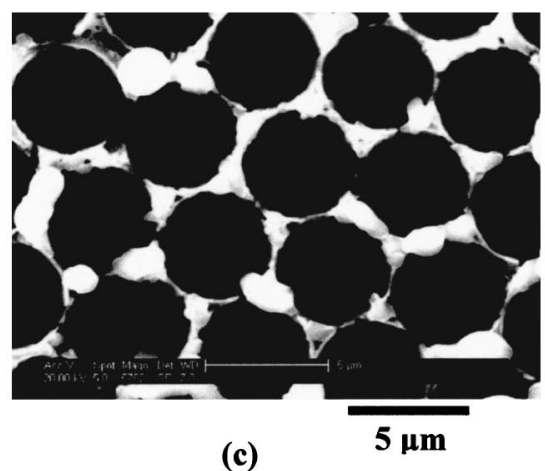

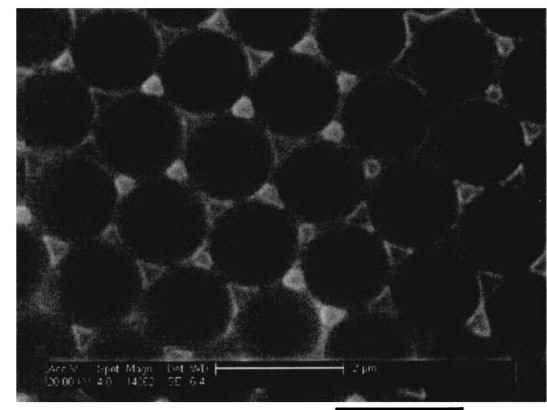

(b) $2 \mu \mathrm{m}$ laser fluence $0.85 \mathrm{~J}^{\mathrm{cm}} \mathrm{cm}^{2}$, (b) $1.54 \mu \mathrm{m}$ particle, laser fluence of $1.4 \mathrm{~J} / \mathrm{cm}^{2}$, (c) $5.06 \mu \mathrm{m}$ particle, laser fluence $1.3 \mathrm{~J} / \mathrm{cm}^{2}$, substrate preheated to $723 \mathrm{~K}$.

\section{B. Influence of particle size on the structuring features}

The size of the created cavities increases with the particle size. The 0.97 hexagonally closed-packed silica particles were imprinted into the $\mathrm{Si}$ substrate by a single laser pulse with a fluence of $0.85 \mathrm{~J} / \mathrm{cm}^{2}$. Ultrasonic agitation was then used to remove the particles. However, some particles still remained on the substrate surface. The sample was then immersed into a HF solution to dissolve the remained silica particles and rinsed by de-ionized water. Figure 3(a) shows the periodical cavity array formed on a Si surface by laser nanoimprinting with $0.97 \mu \mathrm{m}$ silica particles. The resultant cavities reflect the previous positions of the silica particles. With higher magnification shown in 3(b), the SEM analysis reveals that the diameter of the created cavities is about $700 \mathrm{~nm}$ with walls as thin as $20 \mathrm{~nm}$.

Particles with various sizes were used to produce the periodic cavities on $\mathrm{Si}$ substrates. Figure 4(a) shows the SEM image of cavities created on a sample surface using $0.16 \mu \mathrm{m}$ silica particles. The laser fluence was $0.8 \mathrm{~J} / \mathrm{cm}^{2}$. It is revealed that the diameter of the cavity is about $90 \mathrm{~nm}$. The resultant cavities are inhomogeneous in size to some extent due to the wide size distribution of the particles. After laser irradiation by a single pulse with a fluence of $1.4 \mathrm{~J} / \mathrm{cm}^{2}$ on the sample surface, which was self-assembled with $1.54 \mu \mathrm{m}$ silica particles, cavities were created on the Si substrate surface shown in Fig. 4(b). The diameter is about $1.3 \mu \mathrm{m}$.

It was found that $5.06 \mu \mathrm{m}$ silica particles were hard to be imprinted into a $\mathrm{Si}$ substrate at room temperature. Only some debris were found around the cavities after the laser irradiation and the shape of the cavities was not circular. The debris is the Si which was melted and pressed out from the cavities by the particles. To improve the laser imprinting process, the sample was preheated to $723 \mathrm{~K}$ before the laser irradiation. At this temperature the $5.06 \mu \mathrm{m}$ silica particles were imprinted into the $\mathrm{Si}$ substrate with a fluence of $1.3 \mathrm{~J} / \mathrm{cm}^{2}$. Cavities with sharper and more circular edges were created on the surface, which are shown in Fig. 4(c).

\section{Influence of laser fluence on the fabricated cavities}

It was found that the fabricated cavities became bigger as the laser fluence increased. The laser fluence range from 0.9 to $1 \mathrm{~J} / \mathrm{cm}^{2}$ was the best fluence region for the laser nanoimprinting process of $0.97 \mu \mathrm{m}$ particles. Figure 5 shows SEM images of the cavities formed on $\mathrm{Si}$ substrates selfassembled with $0.97 \mu \mathrm{m}$ silica particles by a single laser pulse with fluences ranging from 0.35 to $1.7 \mathrm{~J} / \mathrm{cm}^{2}$. The corresponding lateral dimensions of these cavities range from 0.41 to $0.75 \mu \mathrm{m}$. For laser fluences of 1.3 and $1.7 \mathrm{~J} / \mathrm{cm}^{2}$ [Figs.5(h) and 5(i)], the produced structures are very different from those created with lower laser fluence shown in Figs. 5(a) to 5(g). In Figs. 5(h) and 5(i), craters were formed at the central region in the cavities. Small depressed holes were created at the center of the large craters. Figure 6 shows the sizes of the cavities as a function of the laser fluence.

Simulation of laser interaction with materials (SLIM) (Ref. 21) was used to calculate the thermal process of laser irradiation on Si substrate surfaces. In the calculation, the temporal profile of the excimer laser pulse is approximated 


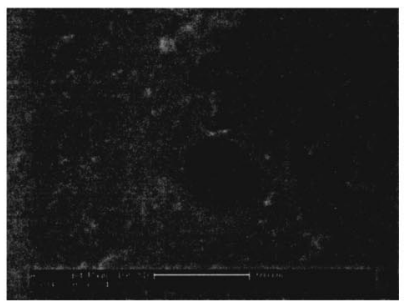

$-200 \mathrm{~nm}$

(a) $0.35 \mathrm{~J} / \mathrm{cm}^{2} 500 \mathrm{~nm}$

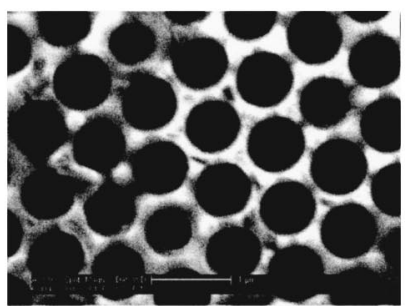

(d) $0.88 \mathrm{~J} / \mathrm{cm}^{2}$

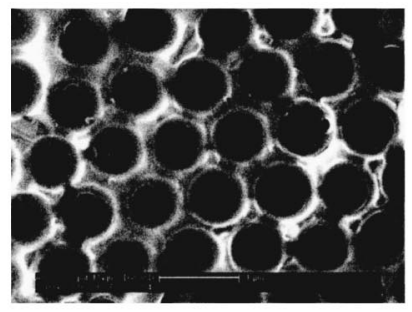

(g) $1.1 \mathrm{~J} / \mathrm{cm}^{2}$

$1 \mu \mathrm{m}$

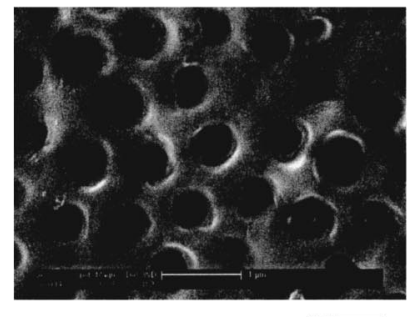

(b) $0.47 \mathrm{~J} / \mathrm{cm}^{2} \quad 1 \mu \mathrm{m}$

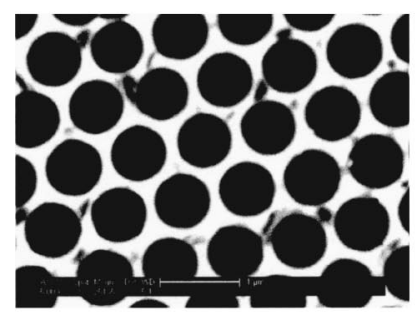

(e) $0.92 \mathrm{~J} / \mathrm{cm}^{2}$

$1 \mu \mathrm{m}$

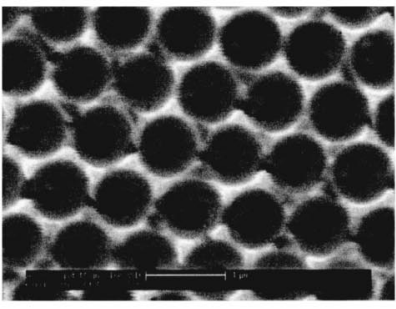

(h) $1.3 \mathrm{~J} / \mathrm{cm}^{2}$
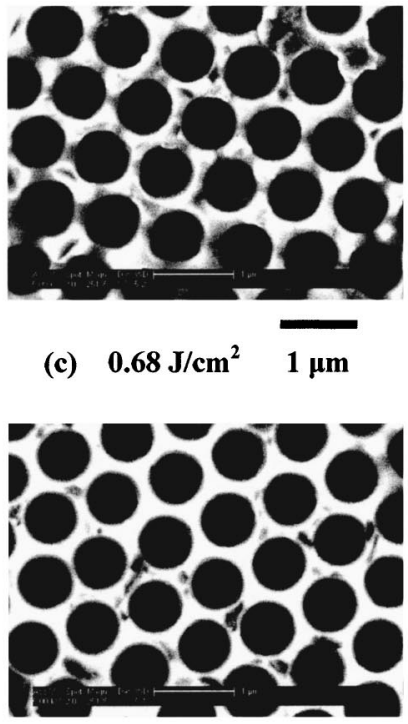

(f) $1 \mathrm{~J} / \mathrm{cm}^{2} \quad 1 \mu \mathrm{m}$

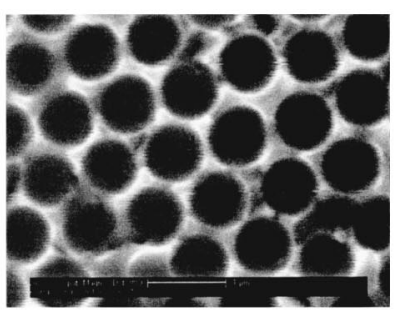

(i) $1.7 \mathrm{~J} / \mathrm{cm}^{2} \quad \overline{1 \mu \mathrm{m}}$

FIG. 5. SEM images of cavities formed by laser irradiation of $0.97 \mu \mathrm{m}$ silica particles on Si substrates by a single laser pulse with fluences ranging from 0.35 to $1.7 \mathrm{~J} / \mathrm{cm}^{2}$

to be a triangular distribution. The original substrate temperature is assumed to be $300 \mathrm{~K}$. In the SLIM model it is assumed that the thermal conductivity of $\mathrm{Si}$ is

$$
\kappa=\left\{\begin{array}{cc}
1585 T^{-1.229} & (T \leqslant 1370 \mathrm{~K}) \\
0.221 & (T>1370 \mathrm{~K})
\end{array}[\mathrm{W} /(\mathrm{cm} \mathrm{K})]\right.
$$

for the solid phase and $\boldsymbol{\kappa}=0.7$ for the liquid phase. The volume heat capacity follows:

$$
c=\left(0.000254 T-36800 T^{-2}+1.988\right)\left[\mathrm{J} /\left(\mathrm{cm}^{3} \mathrm{~K}\right)\right]
$$

for the solid phase and $c=2.4$ for the liquid phase. Reflectivity $R=0.59$ for the solid phase and $R=0.73$ for the liquid phase. Absorption coefficient $\alpha=800000 \mathrm{~cm}^{-1}$ for both solid and liquid phases. Since the silica particles are transparent to $248 \mathrm{~nm}$ laser, they will not absorb the laser beam significantly. The pulse duration at full width at half maximum $t_{\text {FWHM }}$ is $17 \mathrm{~ns}$. The melting temperature and the evaporation temperature of Si are 1685 and $3540 \mathrm{~K}$, respectively.

Laser fluences from 0.35 to $2 \mathrm{~J} / \mathrm{cm}^{2}$ were selected for the calculation of maximum surface temperature and maximum melting depth with laser fluence. The maximum surface temperature of $\mathrm{Si}$ during laser irradiation was calculated. The result shows in Fig. 7(a) that only when laser fluence is higher than $0.55 \mathrm{~J} / \mathrm{cm}^{2}$ will the maximum surface temperature exceed the equilibrium melting point of $\mathrm{Si}$, 1685 K. However, as shown in 5(a), the Si substrate already undergoes melting even if the laser fluence is as low as $0.35 \mathrm{~J} / \mathrm{cm}^{2}$. The reason is that the SLIM deals with the problem in which a laser beam normally irradiates a smooth multilayer substrate without any particles. Whereas in our experiment, the laser beam was normally incident on the substrate surface covered with self-assembled particles. Incident light could excite resonance modes inside the particles

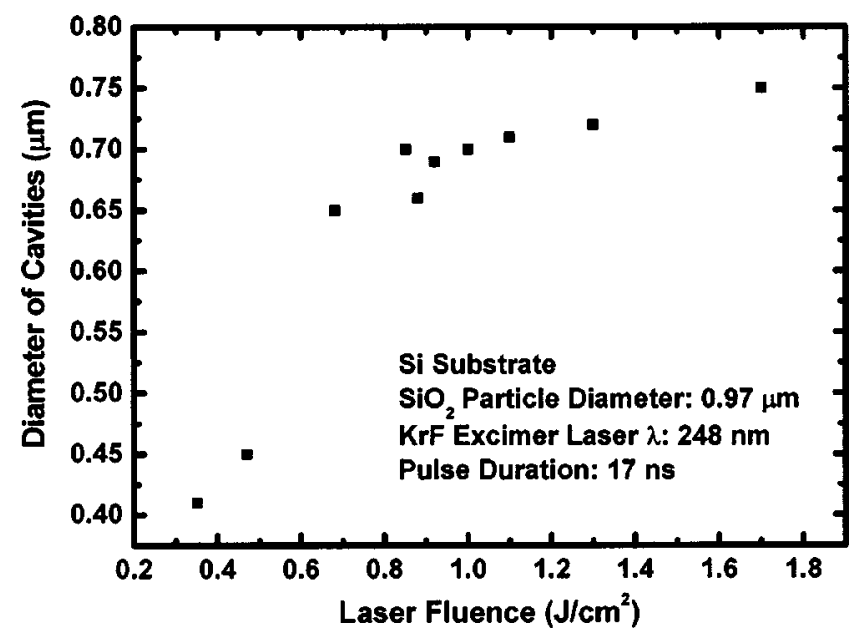

FIG. 6. Diameters of the cavities created on the Si substrate by $0.97 \mu \mathrm{m}$ silica particles with different laser fluence ranging from 0.35 to $1.7 \mathrm{~J} / \mathrm{cm}^{2}$. 


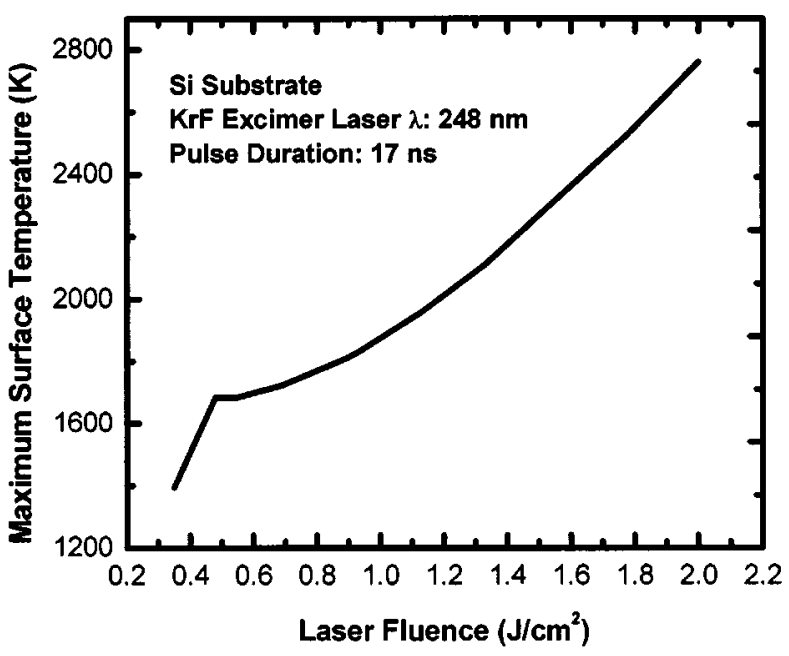

(a)

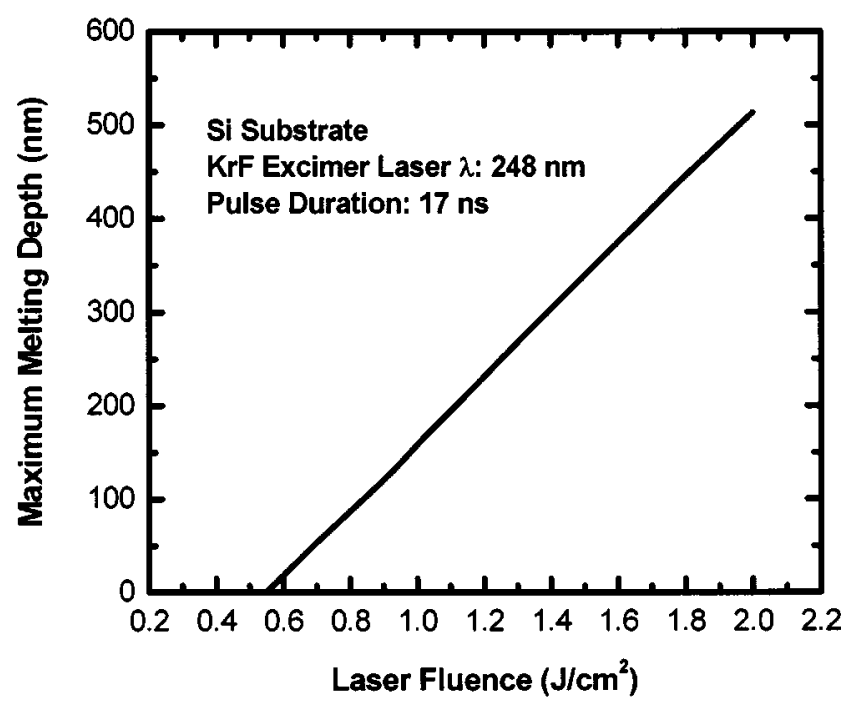

(b)

FIG. 7. Simulation results for the laser irradiation with different laser fluence ranging from 0.35 to $2 \mathrm{~J} / \mathrm{cm}^{2}$ : (a) maximum surface temperature, (b) maximum melting depth of the sample.

as well as produce enhanced light intensities in the contacting regions. ${ }^{16}$ Considering the optical enhancement at the contacting points between the particles and the substrate, a much higher temperature can be reached on the sample surface compared with the results from SLIM. ${ }^{16}$ Although our problem is much more complicated than the conditions used

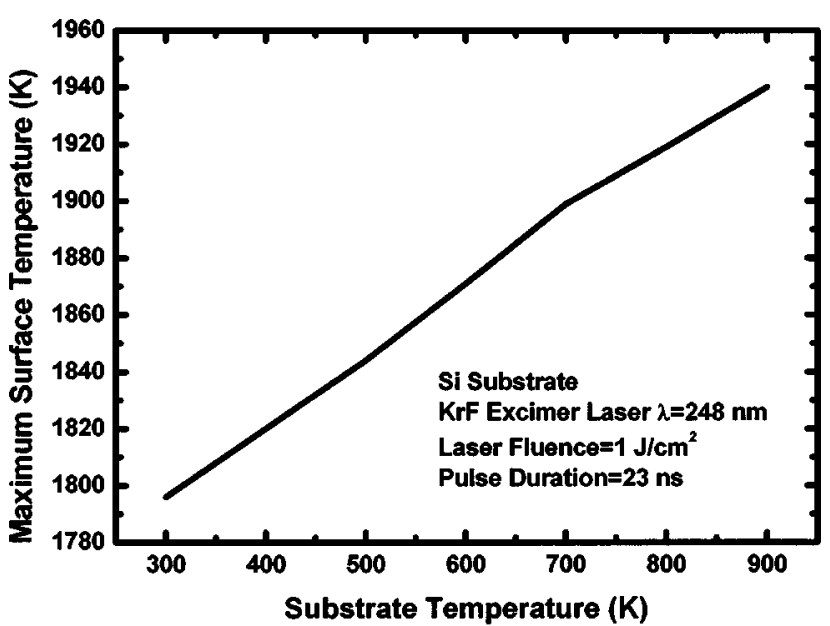

(a)

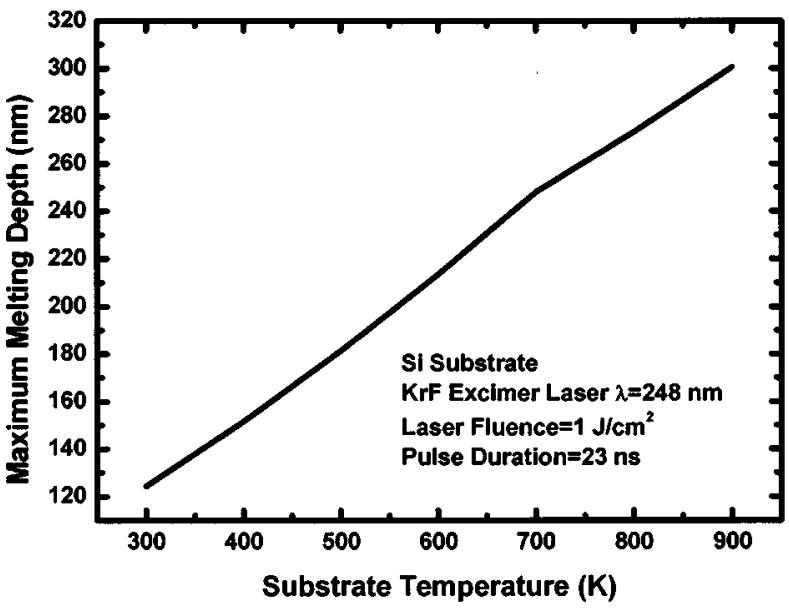

(b)

FIG. 9. Simulation results for $\mathrm{Si}$ substrate with different initial substrate temperatures ranging from 300 to $900 \mathrm{~K}$ during the laser irradiation with a fluence of $1 \mathrm{~J} / \mathrm{cm}^{2}$ : (a) maximum surface temperature and (b) maximum melting depth.

in SLIM simulation, this model can still be used to approximate the thermal effects in the laser nanoimprinting process. The maximum melting depth under different laser fluence was also obtained, as shown in Fig. 7(b). The maximum melting depth increases with the laser fluence. With fluence up to $2 \mathrm{~J} / \mathrm{cm}^{2}$, the maximum melting depth reaches $513 \mathrm{~nm}$. For a laser fluence of $0.85 \mathrm{~J} / \mathrm{cm}^{2}$, the maximum melting depth is $100 \mathrm{~nm}$. However, the experimental value is about

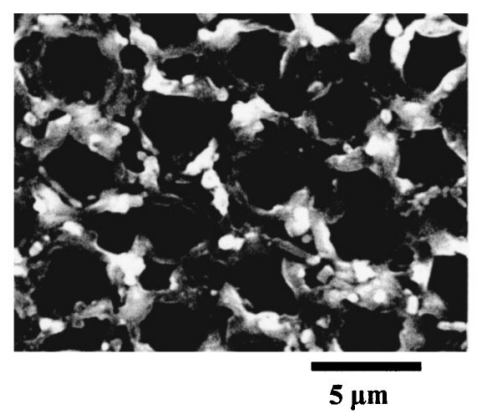

(a) $300 \mathrm{~K}$

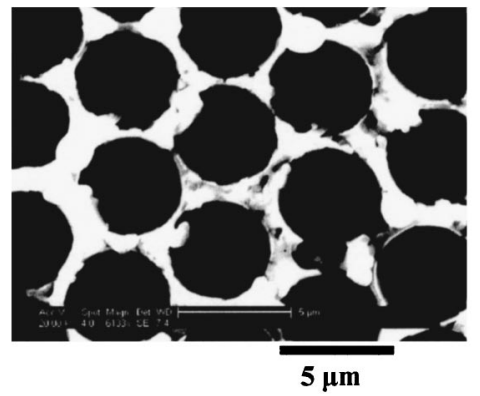

(b) $723 \mathrm{~K}$
FIG. 8. SEM images of the created cavities by a single pulse with a fluence of $1 \mathrm{~J} / \mathrm{cm}^{2}$ after laser irradiation on $\mathrm{Si}$ substrates self-assembled with $5.06 \mu \mathrm{m}$ silica particles: (a) without preheating and (b) preheated to temperature of $723 \mathrm{~K}$. 


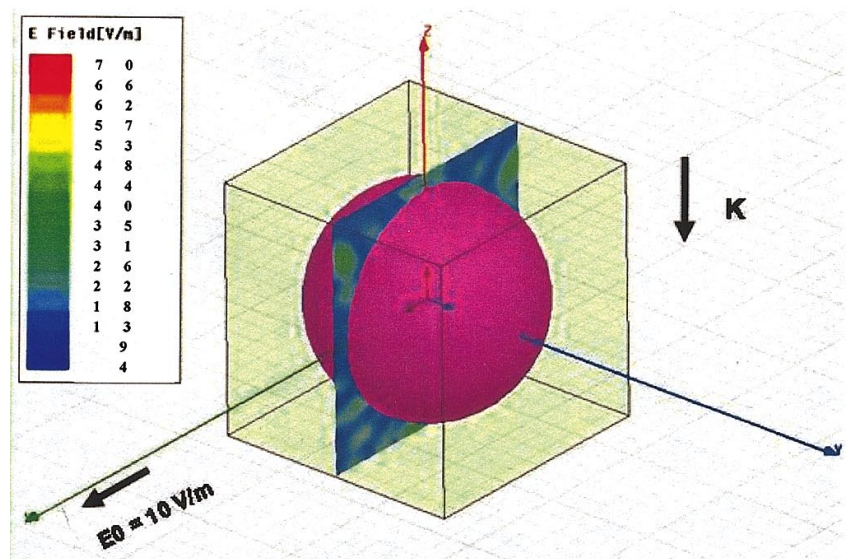

(a)

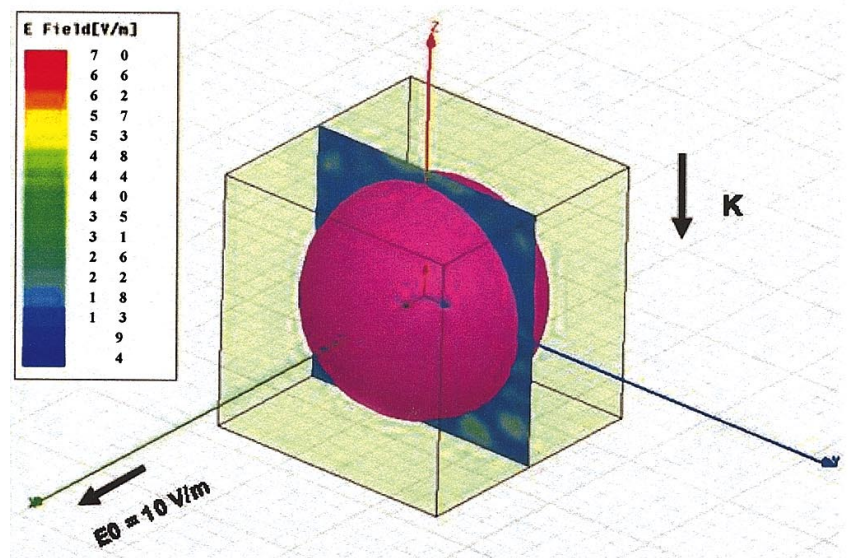

(b)

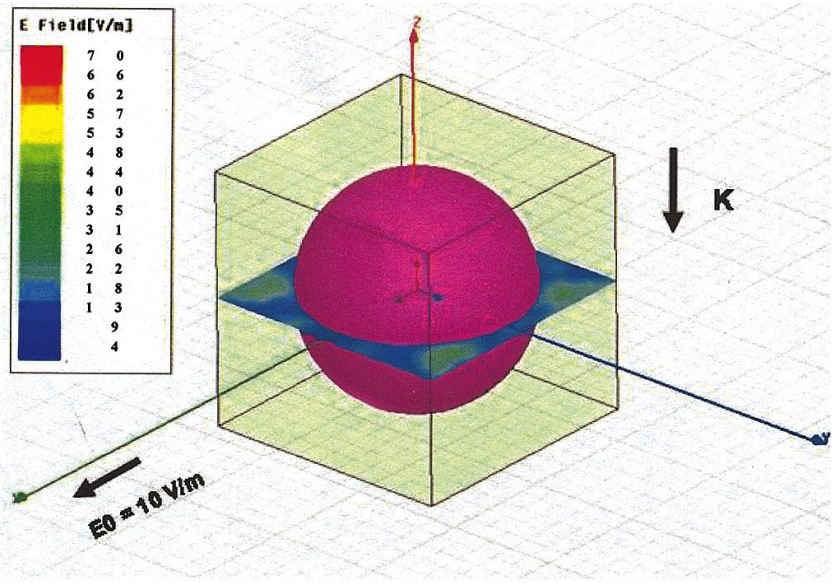

(c)

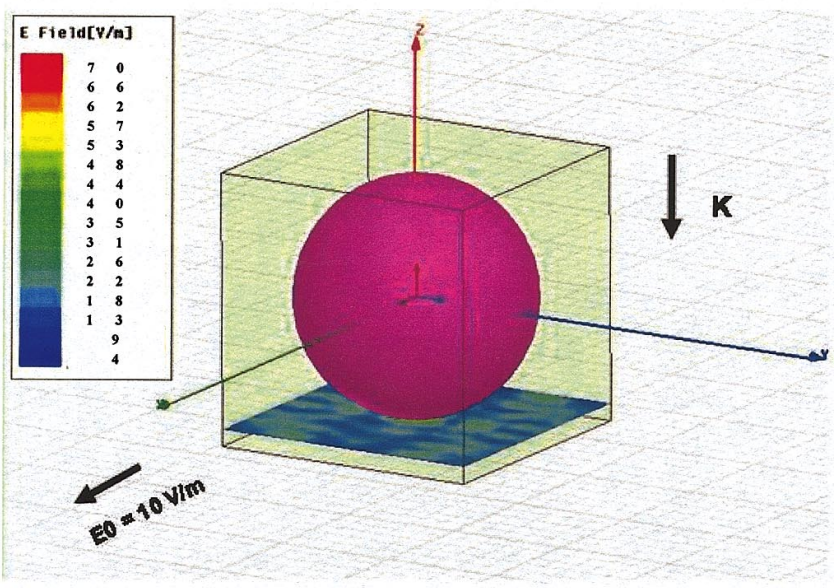

(d)

FIG. 10. (Color) Schematic diagram of the 3D simulation of optical field distribution in different planes for a laser beam going through a $1 \mu \mathrm{m}$ silica particle with an incident magnitude $E_{0}=10 \mathrm{~V} / \mathrm{m}$ : (a) $x-z$ plane, (b) $y-z$ plane, (c) $x-y$ plane, and (d) the particle-substrate contacting plane.

$350 \mathrm{~nm}$. The difference is also due to the light enhancement at the contacting points between the particles and the substrate surface.

\section{Influence of substrate temperature on the cavity structures}

It is found that higher maximum surface temperature of the sample can be reached during the laser irradiation with higher initial substrate temperature. Therefore, it is easier to melt a sample with higher initial substrate temperature and to obtain patterns on it. At room temperature the $5.06 \mu \mathrm{m}$ silica particles were hard to be imprinted into Si substrates and white debris was produced around the cavities after laser irradiation. After preheating the substrate, the quality of the fabricated cavities was greatly improved. To investigate the effect of the substrate temperature, six samples were prepared and preheated to different temperature ranging from 300 to $723 \mathrm{~K}$. Then they were irradiated by a laser pulse with a fluence of $1 \mathrm{~J} / \mathrm{cm}^{2}$. Figure 8 (a) shows that the cavities do not have circular edges and white debris lies around the cavities. When the substrate temperature increases to $373 \mathrm{~K}$, no obvious difference can be observed. When the preheating temperature rises to $473 \mathrm{~K}$, the cavities became more circular and the amount of the debris reduced significantly. When the temperature increases to $723 \mathrm{~K}$, cavities with sharp edges, circular shape, and little debris can be fabricated, as shown in Fig. 8(b).

SLIM was used to theoretically investigate the influence of the substrate temperature on the structuring of the cavities. In the calculation, the temporal profile of the excimer laser pulse is still approximated to be a trianglar distribution. The pulse duration at full width at half maximum $t_{\mathrm{FWHM}}$ is $23 \mathrm{~ns}$. The laser fluence is $1 \mathrm{~J} / \mathrm{cm}^{2}$. All other parameters are the same as before. The maximum surface temperature of the sample during the laser irradiation with a fluence of $1 \mathrm{~J} / \mathrm{cm}^{2}$ preheated with different initial substrate temperature ranging from 300 to $900 \mathrm{~K}$ is delineated in Fig. 9(a). Figure 9(b) shows the maximum melting depth of the sample as a function of initial substrate temperature in a range of 300 to 900 K. Substrates with higher initial substrate temperatures have larger maximum melting depths. Silica particles are consequently more likely to be imprinted into the melted $\mathrm{Si}$ substrate with higher preheating temperature. Therefore, preheating $\mathrm{Si}$ substrate before laser irradiation does contribute to the laser nanoimprinting process. 


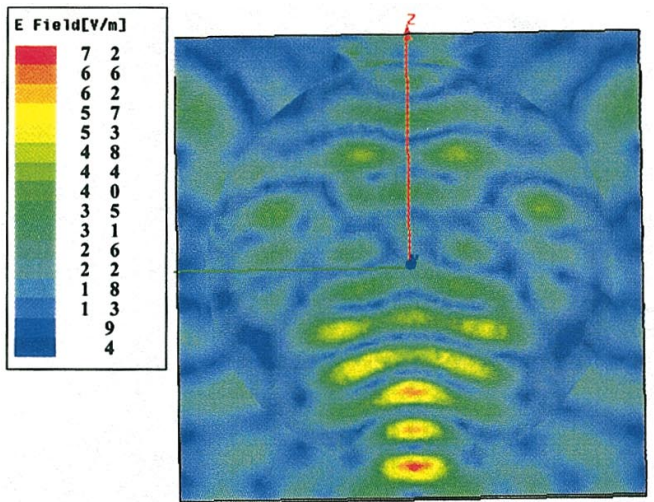

(a)

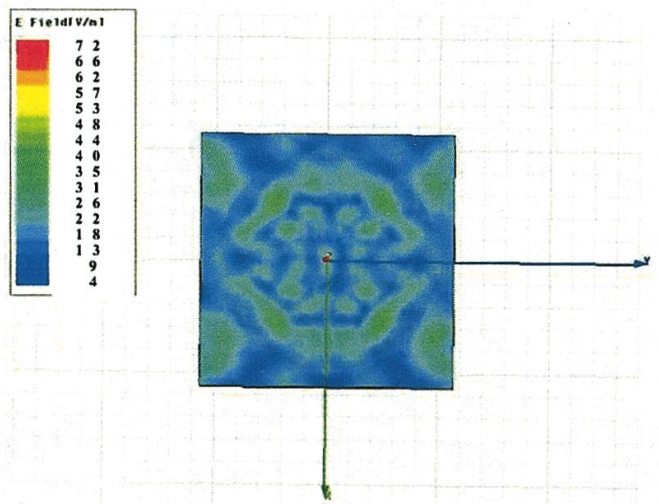

(c)

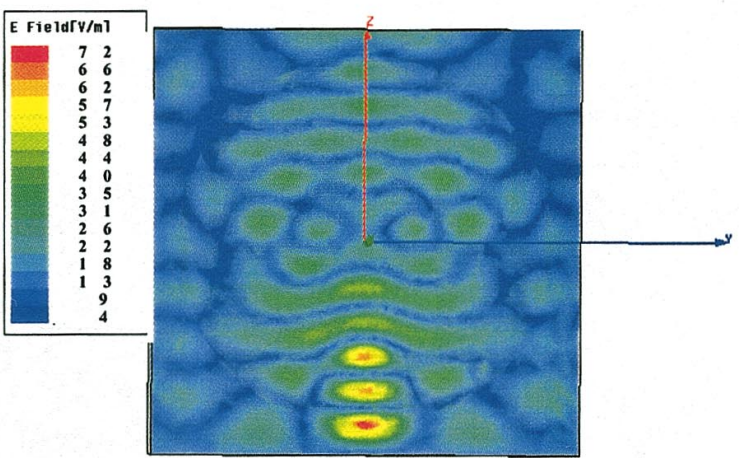

(b)

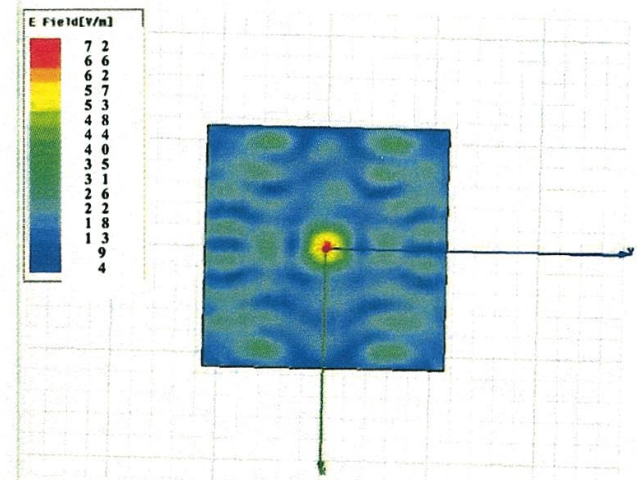

(d)

FIG. 11. (Color) Simulation results of the optical field distribution in different planes for a laser beam going through a $1 \mu \mathrm{m}$ silica particle with an incident magnitude $E_{0}=10 \mathrm{~V} / \mathrm{m}$ : (a) $x-z$ plane, (b) $y-z$ plane, (c) $x-y$ plane, and (d) the particle-substrate contacting plane.

\section{E. Three-dimensional simulation with high frequency structure simulator (HFSS)}

Since SLIM only deals with one-dimensional problems in which a laser beam normally irradiates a smooth multilayer substrate, the light enhancement at the contact points between the particles and the substrate surface has not been considered. High frequency structure simulator (HFSS) (Ansoft software) was employed to give a more accurate three-dimensional insight in this process. In the simulation model, a laser beam with a wavelength of $248 \mathrm{~nm}$ normally irradiates on a $0.8 \mu \mathrm{m}$ silica particles from the top. Assuming the wave propagates along the negative direction of the $z$ axis, the direction of the electric field is along the $x$ axis, and the direction of the magnetic field is along the $y$ axis. The incident magnitude of the electric field is $10 \mathrm{~V} / \mathrm{m}$. Figures 10 (a)-10(d) show the simulation schematic diagrams of the electric field distribution in different planes, i.e., $x-z, y-z, x$ $-y$ and the particle-surface contacting planes, respectively. Figure 11 shows the simulation results of the optical field distribution in the above-mentioned four planes. It is found that the magnitude of the electric field increases about seven times with respect to the incident wave after the wave goes through the silica particle, as shown in Figs. 11(a)-11(d). According to the relation between the light intensity and the magnitude of the electric field

$$
I=c \varepsilon_{0} E^{2}
$$

the light intensity enhancement is about 50 times as compared with the incident wave. Therefore, light energy is confined to the tiny region near the contact point between the particle and the substrate surface. For spherical particles, it is known that they may act as spherical lenses and increase the laser intensity if their diameter is bigger than the laser wavelength. ${ }^{22,23}$ If the diameter of particles is smaller than the wavelength, field enhancement at particles may occur according to the Mie theory. ${ }^{24-27}$

\section{F. Raman spectroscopy of cavity structures}

Raman spectroscopy was used to characterize the stress induced in the cavity structures fabricated by the laser imprinting process. The Raman spectrum of the single-crystal $\mathrm{Si}$ is shown in Fig. 12(a) with a peak position at $520 \mathrm{~cm}^{-1}$. A laser pulse with a fluence of $1.1 \mathrm{~J} / \mathrm{cm}^{2}$ irradiated on a sample self-assembled with $1 \mu \mathrm{m}$ silica particles. The Raman spectra at two different positions on the sample fabricated with the periodic hemispherical cavity arrays have also been taken, as shown in Figs. 12(b) and 12(c). The peak positions of the Raman spectra are 521 and $518.77 \mathrm{~cm}^{-1}$, respectively. The peak intensity and width of both spectra are very similar 


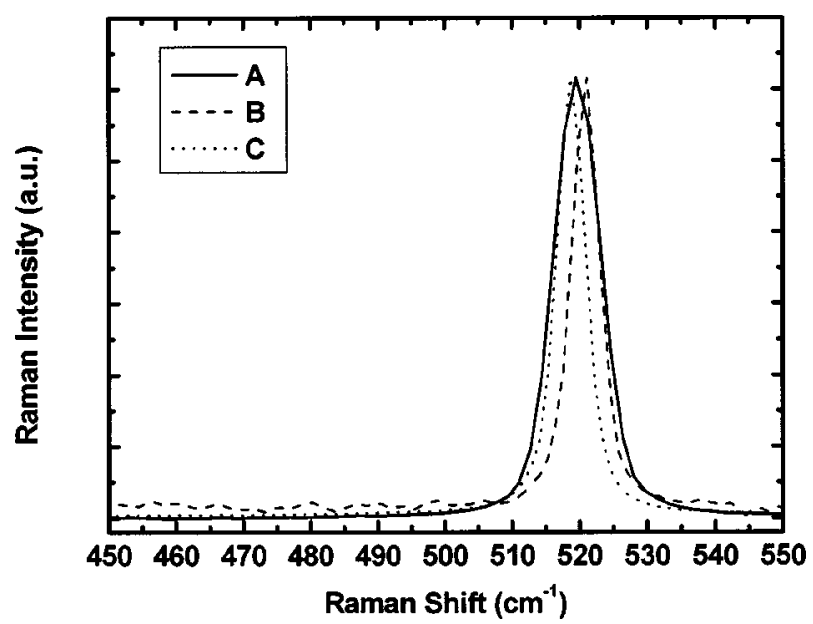

FIG. 12. Raman spectra of (a) the single-crystalline $\mathrm{Si}$, (b) and (c) two different spots on the sample fabricated with periodic hemispherical cavity arrays.

to that of single-crystalline Si samples. Therefore, the stress in the cavity structures induced by the laser imprinting process is not significant.

\section{CONCLUSION}

Laser nanoimprinting of self-assembled silica particles on $\mathrm{Si}$ substrates has been investigated both experimentally and theoretically. Monolayer of silica particles with diameters ranging from 0.16 to $5.06 \mu \mathrm{m}$ have been formed on $\mathrm{Si}$ substrates by the tilting method. The influence of the particle size, laser fluence, and substrate temperature on the cavity structures has been studied. The size of the cavities is dependent on the particle size. The imprinted cavities become larger with laser fluence. For the $0.97 \mu \mathrm{m}$ silica particles, the diameter of the cavities increases from 410 to $750 \mathrm{~nm}$ when the laser fluence increases from 0.35 to $1.7 \mathrm{~J} / \mathrm{cm}^{2}$. Preheating the sample significantly improves the quality of laser nanoimprinting with $5.06 \mu \mathrm{m}$ silica particles. Cavities with sharper and more circular edges can be fabricated after the sample was preheated to $723 \mathrm{~K}$. One-dimensional theoretical calculations of laser interaction with materials have been employed by SLIM for the thermal effect during this process. The calculation reveals that the threshold fluence needed to melt the Si substrate in the experiment is lower than that in the SLIM simulation. The reason is that enhanced light intensities are produced at the particle-substrate contact regions due to the optical resonance inside the particles. 3D HFSS software has been used to simulate the optical field distribution. It is found that the magnitude of the electric field has been increased about seven times after the laser goes through the $0.8 \mu \mathrm{m}$ silica particles. The light intensity has consequently been increased about 50 times. An extremely high temperature is achieved at the contact point between the particle and the substrate, which results in the formation of the cavities. Raman spectroscopy indicates that laser imprinting does not produce significant stress in the fabricated cavity structures.

\section{ACKNOWLEDGMENTS}

This research is funded in part by Air Force Office of Scientific Research (AFOSR, Grant No. F49620-03-1-0426) and National Scientific Foundation (NSF, Grant No. DMI0322922). The authors would like to thank Dr. Gernot Pomrenke (AFOSR) and Dr. Haris Doumanidis (NSF) for their invaluable advices.

${ }^{1}$ P. Ferrand, M. J. Minty, M. Egen, J. Ahopelto, R. Zentel, S. G. Romanov, and C. M. Sotomayor, Nanotechnology 14, 323 (2003).

${ }^{2}$ J. D. Joannopoulos, P. R. Villeneuve, and S. Fan, Nature (London) 386, 143 (1997).

${ }^{3}$ H. Hirayama, T. Hamano, and Y. Aoyagi, Appl. Phys. Lett. 69, 791 (1996).

${ }^{4}$ M. A. McCord, J. Vac. Sci. Technol. B 15, 2125 (1997).

${ }^{5}$ O. Dial, C. C. Cheng, and A. Scherer, J. Vac. Sci. Technol. B 16, 3887 (1998).

${ }^{6}$ S. Y. Chou, P. R. Krauss, W. Zhang, L. Guo, and L. Zhuang, J. Vac. Sci. Technol. B 15, 2897 (1997).

${ }^{7}$ R. F. W. Pease, J. Vac. Sci. Technol. B 10, 278 (1992).

${ }^{8}$ J. P. Silverman, J. Vac. Sci. Technol. B 15, 2117 (1997).

${ }^{9}$ G. M. Wallraff and W. D. Hinsberg, Chem. Rev. (Washington, D.C.) 99, 1801 (1999).

${ }^{10}$ T. Ito, S. Okazaki, Nature (London) 406, 1027 (2000).

${ }^{11}$ A. J. Haes, C. L. Haynes, and R. P. van Duyne, in Nonlithographic and Lithographic Methods of Nanofabrication-From Ultralarge-Scale Integration to Photonics to Molecular Electronics, edited by L. Merhari, J. A. Rogers, A. Karim, D. J. Norris, and Y. Xia, Mater. Res. Soc. Symp. Proc. No. 636 (Materials Research Society, Pittsburgh, 2001).

${ }^{12}$ J. A. Stroscio and D. M. Eigler, Science 254, 1319 (1991).

${ }^{13}$ G. Y. Liu, S. Xu, and Y. Qian, Acc. Chem. Res. 33, 457 (2000).

${ }^{14}$ S. Y. Chou, P. R. Krauss, and P. J. Renstrom, Science 272, 85 (1996).

${ }^{15}$ T. I. Kamins, D. A. A. Ohlberg, and R. S. Williams, Appl. Phys. Lett. 74, 1773 (1999).

${ }^{16}$ S. M. Huang, M. H. Hong, B. S. Lukyanchuk, Y. W. Zheng, W. D. Song, Y. F. Lu, and T. C. Chong, J. Appl. Phys. 92, 2495 (2002).

${ }^{17}$ V. Ng, Y. V. Lee, B. T. Chen, and A. O. Adeyeye, Nanotechnology 13, 554 (2002)

${ }^{18}$ M. Mosbacher, N. Chaoui, J. Siegel, V. Dobler, J. Solis, J. Boneberg, C. N. Afonso, and P. Leiderer, Appl. Phys. A: Mater. Sci. Process. 69, S331 (1999).

${ }^{19}$ F. Burmeister, C. Schäfle, B. Keilhofer, C. Bechinger, J. Boneberg, and P. Leiderer, Adv. Mater. (Weinheim, Ger.) 10, 495 (1998).

${ }^{20}$ J. C. Hulteen and R. P. Van Duyne, J. Vac. Sci. Technol. A 3, 1553 (1995).

${ }^{21}$ SLIM is a copyrighted program developed by Rajiv K. Singh and J. Viatella at Materials Science and Engineering Department at the University of Florida.

${ }^{22}$ S. Hayashi, Y. Kamamoto, T. Sutuki, and T. Hirai, J. Colloid Interface Sci. 144, 538 (1991).

${ }^{23}$ B. S. Luk'yanchuk, Y. W. Zheng, and Y. F. Lu, Proc. SPIE 4065, 576 (2000).

${ }^{24}$ J. A. Stratton, Electromagnetic Theory (McGraw-Hill, New York, 1941).

${ }^{25}$ H. C. Van de Hulst, Light Scattering by Small Particles (Dover, New York, 1981).

${ }^{26}$ C. E. Bohren and D. R. Huffman, Absorption and Scattering of Light by Small Particles (Wiley, New York, 1983).

${ }^{27}$ M. Kerker, The Scattering of Light (Academic, New York, 1969). 